\title{
3
}

УДК 159.98

\section{СМЫСЛОДИДАКТИКА КАК СИСТЕМНОЕ ВОПЛОЩЕНИЕ ОБЩЕЙ ТЕОРИИ СМЫСЛА В ПРАКТИКЕ УЧЕБНОГО ПРОЦЕССА}

\author{
Абакумова Ирина Владимировна \\ Кукуляр Анна Михайловна \\ Фоменко Владимир Трофимович
}

Авторы исходят из того, что, согласно современной психологии и ряду других гуманитарных наук, смыслы являются основной единицей сознания человека, они - высшая инстанция саморегуляции его жизнедеятельности. Отсюда вытекает необходимость смыслообразования обучающихся как доминантной ориентации образовательного прочесса и, прежде всего, обучения как главного механизма образования. Данное обстоятельство предписывает решение ряда практических задач при переходе на смысловую парадигму учебного процесса. Одна из них - овладение учителем (преподавателем) по существу новым дидактическим тезаурусом, в рамках которого переосмысливаются классические понятия челеполагания, содержания, методов и технологий обучения. С этим связана необходимость соответствующей трансформации традиционных, когнитивных компетенций обучающихся в смыслодеятельностные, смыслотворческие. Заметно меняется общение учителя и учащегося, преподавателя и обучающегося, приобретая характер смыслового резонанса. Эти и другие задачи, системно и челостно связанные с переосмыслением педагогических практик на основе смыслообразующей деятельности участников учебного прочесса, и решаются в статье.

Ключевые слова: смыслодидактика, смыслообразование, смыслообразующее обучение, смыслообразующие ситуации, смыслодидактика в обучении.

\section{SENSE-DIDACTICS AS A SYSTEM IMPLEMENTATION OF THE GENERAL THEORY OF SENSE IN THE PRACTICE OF THE EDUCATIONAL PROCESS}

\author{
Abakumova Irina Vladimirovna \\ Kukuliar Anna Mikhailovna \\ Fomenko Vladimir Trofimovich
}

The authors proceed from the assumption that, according to modern psychology and some other humanities, senses are the main unit of the person's consciousness; 


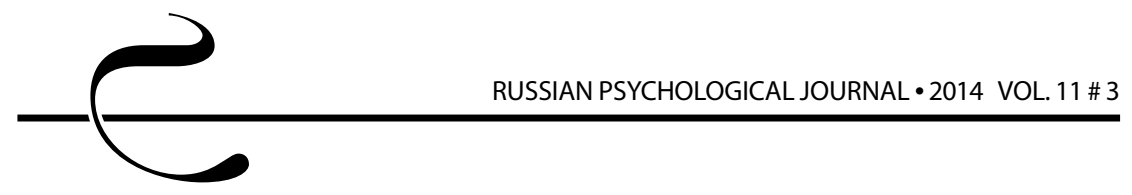

they are the highest level of his/her life activity self-regulation. Hence it follows that sense-creation of learners must be a dominant orientation of the educational process and especially learning as the main mechanism of education. This circumstance requires solving of a number of practical problems in passing to a sense paradigm of the educational process. The teacher's (lecture's) acquisition of an inherently new didactic thesaurus within which he/she reinterprets classical concepts of the content, methods, technologies, and goal-setting of education is one of such problems. This involves the necessity of a corresponding transformation of traditional, cognitive competences of learners to sense-activity, sense-creative ones. Communication of the teacher and the pupil, the lecturer and the student changes considerably, becoming a sense resonance. The authors solve these and other problems systemically and completely connected with reconsideration of pedagogical practices on the basis of sense-creative activity of the educational process participants.

Keywords: sense-didactics, sense-creation, sense-creating education, sensecreating situations, sense-didactics in training.

В научных исследованиях последнего времени все заметнее отражаются различные аспекты смысла, в совокупности образующие контуры его общей теории. Речь идет о семиотическом, синергетическом, аксиологическом, экзистенциальном, философском подходах к смыслу, не говоря уже об усиливающемся внимании к нему со стороны психологов. Несмотря на разнообразие подходов, исследователи едины во мнении, что смыслы есть высшая инстанция саморегуляции жизнедеятельности человека. В отличие от значений, являющихся единицей мышления, смыслы - единицы сознания, к значениям здесь плюсуется пристрастность $[1,6,9]$. Если значения в процессе познания выражают объективные связи окружающей человека действительности, то смыслы выражают его отношение к данной действительности и тем самым связывают человека с миром.

Удивительно, но факт: дидактика, возможно, в силу недостаточного уровня самой теории смысла, может быть, в силу собственной недостаточности, всегда обходила смыслы, замыкаясь на значениях. Неслучайно А. Н. Леонтьев, психологическая теория смысла от которого и берет, можно сказать, начало, с горечью писал, что «наш учебный процесс насыщен значениями и не насыщен смыслами» [6]. Эти слова, по крайней мере, в некоторой степени, можно отнести и к состоянию современного учебного процесса. Даже развивающее обучение, достигшее в отечественном образовании несомненных успехов, «застревает» на уровне мышления, а обеспечивающая его дидактика остается когнитивной.

Между тем возникает вопрос о привнесении в учебный процесс именно смысловой составляющей. В рассказе О'Генри «Дороги, которые мы 
выбираем» проводится мысль, что главное заключается даже не в том, какую дорогу в жизни выбирает человек, а в том, что есть в человеке такого, благодаря чему он выбирает тот или иной путь [1, 2]. Ясно, что речь идет о смыслах. В нашем многолетнем эксперименте, проводимом в г. Ростове-на-Дону, а теперь и на более обширных территориях, обучение выступает как смыслообразующий процесс, его глобальная цель - смысловое приращение обучающихся. Даниил Гранин устами своего героя, а герой устами А. Эйнштейна, бросает фразу: «Образование есть то, что остается в человеке, когда все выученное забыто». Что же остается в человеке, когда все выученное забыто? Остаются крупные, организующие знания, способы деятельности, опыт, позиции, взгляды, научная картина мира, когнитивные схемы мышления, фоны познавательной деятельности, установки, интенции. Этот ряд понятий и концептов в нашем направлении педагогики, обозначенном нами и звучащем как смыслодидактика, призван обеспечить смыслообразующее обучение научной методологией и технологиями, но и сам он продолжается смысловыми матрицами, или, иначе, кодами сознания. Смысловые матрицы, коды сознания - своего рода смысложизненные ориентиры человека, и, следовательно, дидактическое целеполагание и продукты дидактического процесса в оптимально организованном обучении их миновать не могут. Более того, каждая из названных констант: организующие знания, способы деятельности, опыт, позиции и т. д. - заключает в себе смысловой потенциал, все они - смысловые единицы жизни $[1,2,6,7]$, но смыслы, смысловые матрицы, коды сознания возвышаются и над ними как весьма значимыми целями и результатами обучения и образования в целом $[1,2,3,9,11]$.

В смысловой дидактике и ее практической реализации мы пошли значительно дальше. Учитывая известную максиму классиков «цель как способ определяет собою характер деятельности», пришлось в соответствии со смыслообразующей ориентацией учебного процесса обновлять, по существу, все его базовые компоненты.

Изменению, в частности, подвергнуты классические принципы обучения. Согласно одному из них - принципу сознательности - понимание есть сердцевина обучения, согласно нашей дидактике - непонимание есть сердцевина обучения как момент движения к пониманию. При этом мы исходим из того, что «смысл есть всегда смысл чего-то» и при этом он «всегда есть мой смысл» $[1,6,10,11]$. В подлинном учебном процессе возникает необходимость «докопаться» до смысла изучаемого материала («смысл чего-то») и тем самым инициировать удивление или иное значимое эмоциональное состояние («мой смысл»). То и другое предполагает преодоление барьеров, момент сопротивления материала. Каждый из классических принципов 
несет на себе печать подобных трансформаций, вызванных смысловыми целевыми установками.

В смыслодидактике известные классические принципы не только подвергнуты смысловой субъективации, но и продолжены группой не столь масштабных, но явно более глубоких принципов, обеспечивающих реализацию смыслообразующей функции обучения. Среди них - принцип проблемности, принцип интеграции, принцип вариативной организации учебного процесса обучения. В данной группе обнаруживается и принцип смыслообразования. Опять же, каждый из названных принципов испытывает на себе влияние принципа смыслообразования.

В еще большей мере переосмысливается содержание учебного процесса. В классической дидактике оно определяется как то, что подлежит усвоению, овладению - это целевые характеристики содержания, следующие из когнитивной дидактики. В смысловой дидактике оно предстает как та субстанция, которая питает развитие учащихся, можно сказать и шире, - обучающихся, включая студентов.

Реально выстраивая учебный процесс на смыслообразующей основе, особое внимание следует обратить на следующие два момента.

Один из них состоит в том, что смыслы высекаются на стыке разнохарактерных знаний. Смысл одного содержания постигается через смысл другого содержания. Отсюда значение межпредметной интеграции, включая взаимно удаленные учебные курсы (спецкурсы «Достоевский и Эйнштейн», «Математика и искусство») [1, 2, 3, 4]. В эксперименте, о котором было сказано выше, смыслы выступают в роли интегрирующих факторов. Возникающие при этом «пограничные области» - источник развития интегративного сознания учащихся, базируемого на смыслах более высокого уровня, в сравнении с предметным обучением. Таким образом, смысловой подход ограничивает предметоцентризм.

Другой момент, выражающий обновление содержания обучения в условиях его смыслообразующей направленности и реализации, состоит в осознании учебных текстов как носителей смыслов человеческого бытия. Как писали классики гуманистической философии, «текст есть дух в плену знаков» $[1,2]$. Задача учебного процесса заключается в том, чтобы высвободить дух из плена знаков, а дух - это, прежде всего, смыслы, хотя, естественно, и мысли, и информация, и что-то еще. Имеющий в рассматриваемой дидактике место смыслоцентризм не подавляет другие атрибуты содержания, а поднимает их на новый, ценностный уровень. Укажем также, что «высвобождение» духа - особая, смысловая разновидность известного в психологии феномена интериоризации. Содержание текстов в их знаковой форме имеет отчужденный от учителя и учащихся характер, заключенные 
в них смыслы - редуцированный, свернутый вид. При соприкосновении сознания с текстом, как писал М. К. Мамардашвили, оно и институируется [1]. Содержание становится содержанием деятельности учащихся в виде движения идей, понятий, процедур действий, но главное - смыслов, эмоций, переживаний, за которыми скрываются все те же смыслы. Процесс обучения в этом случае - еще не ставшее, но уже становящееся бытие. Наконец, на стадии выхода из учебного процесса содержание обретает форму ставшего бытия, является содержанием личности, доминанта которого - упомянутая выше смысловая матрица.

Если в наших исследованиях смысла смысловая составляющая содержания и содержание в целом питают развитие учащихся, то образовательные технологии - включают, запускают их развитие, в интересующем нас плане - развитие смысловой сферы, смыслосферы, как еще можно сказать. Общая теория смыслов перед дидактикой, желающей исповедовать принцип смыслообразования, ставит при этом ряд барьеров, разрешение которых и поднимает ее на уровень смыслодидактики. Один из таких барьеров заключается в том, что, согласно теории, смыслам не учат и смыслам не учатся смыслы возникают, являются, постигаются, извлекаются, обогащаются, гаснут $[1,2,6,7,11]$. Явный парадокс, поскольку обучение потому и называется обучением, что в нем одни учат, а другие учатся. Барьер преодолевается и парадокс исчезает, если в задачу учителя включить инициацию таких психолого-дидактических ситуаций, в процессе выхода из которых смыслы и извлекаются, постигаются, осознаются, обогащаются.

Управление познавательной деятельностью учащихся в изложенном фрагменте нашего исследования осуществляется, как можно видеть, через ситуации и имеет косвенный, опосредованный характер. Согласно Л. В. Занкову, чтобы добраться до «смысла чего-либо», обучение может принять сложную, криволинейную структуру с «забеганием вперед» и «возвращением назад». Подобные зигзаги могут иметь место, если содержание смысла на конкретном данном этапе не раскрывается и приходится искать обходные пути.

Далее, смысловой подход к обучению, некоторые его элементы и аспекты заметно сказываются на дифференциации и ее крайнем выражении - индивидуализации обучения. Смысловые приоритеты конкретных учащихся здесь «работают» в полную силу на индивидуальность, дифференциация переходит в ранг самодифференциации $[1,10]$. Если учитель просит учащихся подойти к окну, посмотреть на небо и написать миниатюрное сочинение на тему о том, что каждый из них увидел в проплывающем облаке, то это и может служить примером самодифференциации: один увидел «парус одинокий» и пишет о нем, другой - верблюда, а третий - математические сфероиды. 
Здесь слабо просматривается путь к асинхронному обучению, о котором немало разговоров.

Какой аспект учебного процесса ни возьми, взирая на него с позиций смыслообразования учащихся, обнаруживается явно нетрадиционная дидактика. Она, неклассическая дидактика, так и звучащая в наших исследованиях, обогащает, например, номенклатуру дидактических закономерностей. Из известных закономерностей несомненно когнитивного толка можно назвать обучение от предметного плана действия к внешнеречевому и от него к внутреннему, свернутому, сокращенному; от ориентировочной основы действий - к операциональной структуре; от концептуального образа - к моделированию основных признаков, и от него - к их интеграции; от хаотического множества элементов - к их системе; от собственного, личного опыта детей - к их академической деятельности. Исходя из того, что не только смысловые структуры человека определяют во многом траекторию его жизни, но и сама жизнь в немалой степени обусловливает смысловую матрицу личности, дидактическая закономерность в наших исследованиях и собственном педагогическом опыте звучит как обучение от жизненного мира ребенка; жизненный же мир его не ограничивается личным и даже личностным опытом - он всегда замкнут на объективных ценностях культуры и бытия.

Смыслодидактика, если брать очередной ее аспект, ориентирует на развитие творческой, креативной сферы обучающихся.

Мы исходим из того, что «творчество бескорыстно, оно ничего не требует взамен». Исходим из того, что творчество не любит методик, технологий, оно любит поддержку - психологическую, дидактическую. В «обычном» обучении, в том числе смыслообразующем, обучающийся поглощает дух текстов; здесь же он созидает тексты, откристаллизовывая в них смыслы собственного бытия. В традиционном обучении, о котором частично была речь, если исходить из известной максимы «быть личностью», учебный процесс приобретает формирующую окраску; в «смыслодидактике», следуя максиме «быть самим собой», он имеет характер самовыражения обучающегося, характер раскрытия, раскрывающего обучения $[8,10,11]$. Здесь учащиеся - авторы или соавторы нового содержания, новых текстов. Если раньше речь шла об интериоризации в смыслообразующем обучении, здесь мы говорим об экстериоризации.

Смыслодидактика, следовательно, - это в заметной степени креативная дидактика.

С позиции смыслодидактики мы посмели посягнуть и на незыблемый, казалось, тезаурус классической дидактики, как и выражаемую им реальность обучения. Что имеется в виду? 
1. Общение, совместная деятельность учителя и учащихся рассматриваются в таких понятиях, как смысловой резонанс, смысловой диссонанс.

2. Главные движущие силы процесса обучения определялись и все еще определяются как противоречие между наличным уровнем знаний и поступающими от учителя знаниями, рассогласованием имеющейся и новой информации. В нашей концепции и педагогическом обиходе указанное рассогласование - это несовпадение смыслов учителя и учащихся относительно осваиваемых значений.

3. Основная линия движения обучения, совпадающая с логикой учебного предмета, истолковывалась как последовательность знаний и сопровождающих их умений, навыков, способов деятельности. В смыслодидактике эта линия образуется логикой становления самой личности, ее жизненного мира, развитием ее смысловых структур и самосознания, а не только и не столько логикой науки. Сциентизм, означающий построение учебного процесса по способу научного исследования, нами не отрицается - в нем реализуются свои смыслы, - но он все же ограничен обращением к смыслам культуры - и смыслам бытия вовне.

4. В смыслодидактике усилено внимание логике учебного процесса. Логика учебного процесса - это логика реального процесса, в то время как логика учебного предмета, зависящая от конкретных обстоятельств, определяет лишь общий вектор обучения. Получающие распространение «задачи на смысл», задачи реального типа, содержащие, казалось бы, незначительные факты, отбрасываемые в академических задачах, а на самом деле заключающие в себе важные смыслы, - все это примеры проявления логики учебного процесса, бесконечно многообразной и вариативной.

Из сказанного следует, что общую теорию смысла удалось системно воплотить в одной из наиболее значимых областей человеческого бытия и человеческой культуры - в образовании. Тем самым создан прецедент подобного воплощения общей теории смысла и психологических концепций смыслообразования в различных областях жизнеобитания и жизнедеятельности человека. Обучение предстает в нашей концепции как смысловая реальность, а значит, как смысловая реальность могут предстать и другие сферы жизни, например: математика, физика, медицина, эстетика.

Несколько слов о научно-психологическом и научно-дидактическом обеспечении практики реализации «Смыслодидактики». Указанное обеспечение имеет комплексный характер. Смыслообразующее обучение в нашем педагогическом опыте обеспечено монографией, учебником, хрестоматией, сборником тестовых заданий, смыслодидактикой в схемах $[1,2,3,4,5,9]$. Данный факт - тоже своеобразный прецедент к психолого-дидактическому обеспечению процессов реализации смыслообразующих концепций различных уровней и содержания. 
В заключение заметим, что в настоящее время в общей дидактике и ее отдельных аспектах наблюдается заметный прогресс. Она, возможно, на грани выхода из общей педагогики. Ее иногда и сейчас называют наукой. Наблюдается и другая тенденция - размываются границы в самой педагогике между дидактикой и иными ее разделами, и не исключено, что дидактика исчезнет, значительно обогатив педагогику. В одном и другом случае сказанному уже способствует «Смыслодидактика», несмотря на ее очевидную молодость.

\section{Литература}

1. Абакумова И. В. Обучение и смысл: смыслообразование в учебном процессе. - Ростов н/Д: Изд-во РГУ, 2003.

2. Абакумова И. В. Смыслодидактика. Учебникдля магистрантов психологии и педагогики. - М.: КРЕДО, 2008.

3. Абакумова И. В., РудаковаИ. А. Смыслодидактика в структурно-логических схемах. Учебное пособие для магистров педагогики и психологии. - М.: КРЕДО, 2009.

4. Абакумова И. В., РудаковаИ. А. Смыслодидактика: оценочные средства аттестации магистрантов. Учебно-методическое пособие. - М.: КРЕДО, 2012.

5. Абакумова И. В., Рудакова И. А. Смыслодидактика: тестовые задания. Учебно-методическое пособие для магистрантов педагогических и психологических специальностей. - М.: КРЕДО, 2012.

6. Леонтьев А. Н. Деятельность. Сознание. Личность. - 2-е изд. - М.: Политиздат, 1977.

7. Леонтьев Д. А. Психология смысла. - М.: Смысл, 2000.

8. Лотман Ю. М. О поэтах и поэзии. - СПб.: Искусство, 1996.

9. Общая теория смысла, психологические концепции смыслообразования, смыслодидактика. Хрестоматия для магистрантов педагогики и психологии / Сост. Абакумова И. В., Ермаков П. Н., Рудакова И. А. - М.: КРЕДО, 2014.

10. Фоменко В. Т. Исходные логические структуры процесса обучения. Ростов н/Д: Изд-во РГУ, 1985.

11. Франкл В. Человек в поисках смысла. - М.: Прогресс, 1990.

\section{References}

1. Abakumova I. V. Obuchenie i smysl: smysloobrazovanie v uchebnom protsesse [Education and sense: sense-creation in the educational process]. Rostovon-Don, Rostov State University Publ., 2003.

2. Abakumova I. V. Smyslodidaktika. Uchebnik dlia magistrantov psikhologii i pedagogiki [Sense-didactics. Textbook for master students in psychology and pedagogics]. Moscow, KREDO Publ., 2008. 
3. Abakumova I. V., Rudakova I. A. Smyslodidaktika v strukturno-logicheskikh skhemakh. Uchebnoe posobie dlia magistrov pedagogiki i psikhologii [Sensedidactics in structural and logical schemes. Textbook for master students in psychology and pedagogics]. Moscow, KREDO Publ., 2009.

4. Abakumova I. V., Rudakova I. A. Smyslodidaktika: otsenochnye sredstva attestatsii magistrantov. Uchebno-metodicheskoe posobie [Sense-didactics: evaluative means of master students' certification. Educational and methodical textbook]. Moscow, KREDO Publ., 2012.

5. Abakumova I.V., Rudakova I. A. Smyslodidaktika:testovye zadaniia. Uchebnometodicheskoeposobie dlia magistrantov pedagogicheskikhipsikhologicheskikh spetsial'nostei [Sense-didactics: test tasks. Educational and methodical textbook for master students in pedagogical and psychological specialties]. Moscow, KREDO Publ., 2012.

6. Leont'ev A. N. Deiatel'nost'. Soznanie. Lichnost' [Activity. Consciousness. Personality]. Moscow, Politizdat Publ., 1977.

7. Leont'ev D. A. Psikhologiia smysla [The psychology of sense]. Moscow, Smysl Publ., 2000.

8. Lotman lu. M. O poetakh i poezii [On poets and poetry]. St. Petersburg, Iskusstvo Publ., 1996.

9. Abakumova I. V., Ermakov P. N., Rudakova I. A. Obshchaia teoriia smysla, psikhologicheskie kontseptsii smysloobrazovaniia, smyslodidaktika. Khrestomatiia dlia magistrantov pedagogiki i psikhologii [The general theory of sense, psychological concepts of sense-creation, sense didactics. Reading book for master students in psychology and pedagogics]. Moscow, KREDO Publ., 2014.

10. Fomenko V. T. Iskhodnye logicheskie struktury protsessa obucheniia [Initial logical structures of the educational process]. Rostov-on-Don, Rostov State University Publ., 1985.

11. Frankl V. Chelovek v poiskakh smysla [Man's search for meaning]. Moscow, Progress Publ., 1990. 